\section{Interaction of Human Recombinant Tumor Necrosis Factor-Related Apoptosis-Inducing Ligand and Osteoprotegerin Could Contribute to Enhancement of the Erosive Processes Induced by Human Synovial Cells}

\section{To the Editor:}

Rheumatoid arthritis (RA) is a chronic inflammatory disease for which the etiology is unknown. Patients with RA are known to have lower bone mineral density and are at risk of pathological fracture caused by cytokines produced by RA synovial fibroblasts, which have the potential to promote osteoclast formation and bone resorption. It is now clear that osteoclast formation and activation at the cartilage-pannus junction is an essential step in the destruction of bone matrix in $\mathrm{RA}^{1,2}$

Our aim was to investigate key factors that regulate focal bone erosion in RA, and their relationships with human recombinant tumor necrosis factor (TNF)-related apoptosis-inducing ligand (hr-TRAIL), in order to propose a strategy to block bone destruction in RA.

A number of inflammatory cytokines found in the RA synovial tissue [interleukin 1 (IL-1), IL-1ß, IL-6, TNF- $\alpha$, and macrophage colony-stimulating factor] have the potential to promote osteoclast formation and bone resorption ${ }^{3,4}$. Cells within RA synovial fibroblasts also are substantial sources of soluble receptor activator of nuclear factor- $\mathrm{KB}$ (sRANKL) and osteoprotegerin (OPG), establishing a contribution of these cytokines to the process of erosion ${ }^{5}$

Bone erosion depends mainly on the synergistic action of these cytokines, where RANKL, produced by osteoblasts, fibroblasts, and T cells, and receptor activator of nuclear factor B (RANK) are mainly expressed on pre-osteoclasts, possibly of the macrophage lineage ${ }^{6-9}$. TRAIL, a member of the TNF protein family along with RANK and RANKL $^{10}$, with which it shares homology, could be a key factor in this process. TRAIL is able to induce cell death ${ }^{11}$ through association with the death-domain-containing receptors TRAIL-R1 (DR4) and TRAIL-R2 (DR5) ${ }^{12,13}$. In addition to the 2 decoy receptors already discussed, a third decoy receptor and a fifth receptor for Apo2L/TRAIL has also been described, namely $\mathrm{OPG}^{10}$. OPG is a soluble member of the TNF receptor family, for which the best-described action is the inhibition of RANKL-stimulated osteoclast formation. OPG can bind to RANKL and prevent interaction with its cognate receptor, RANK; however, OPG can also interact with Apo2L/TRAIL ${ }^{10}$. Since the prevalence of OPG expression is a critical determinant of the degree to which RANKL can stimulate osteoclast generation and activation, we examined the expression of OPG and RANKL proteins in RA synovial fibroblasts. Interestingly, Colucci, et $a l^{14}$ recently demonstrated that osteoclastogenesis can still occur in vitro in the presence of high OPG concentrations due to the formation of OPG/TRAIL complexes, possibly leading to the sequestration of OPG by TRAIL, which subsequently prevents its binding to RANKL. Therefore, the localization of OPG in the RA bone microenvironment could be contributing to the erosive process, rather than being inhibitory. To elucidate the important relationship between RANKL, TRAIL, and OPG in human RA synovial fibroblasts we analyzed RANKL and OPG expression after administration of $100 \mathrm{ng} / \mathrm{ml}$ of human recombinant TRAIL. RA synovial fibroblasts also produce a basal level of RANKL (Figure 1, right side, C1, D1 green fluorescence) and OPG (Figure 2), making them capable of influencing the erosion process; this is illustrated in Figure 1 by the use of a TRAP immunoenzymatic assay in which cells without TRAIL (Figure 1B) are less TRAP-positive versus the cells treated with TRAIL (Figure 1B.1). Moreover, cells treated without recombinant human-TRAIL show results less differentiated toward the osteoclast phenotype compared to the TRAIL-treated cells, as indicated by the formation of multinucleated cells. As shown in Figure 2 the addition of $100 \mathrm{ng} / \mathrm{ml}$ recombinant humanTRAIL induced a significant upregulation of RANKL and simultaneously a downregulation of OPG. In addition, OPG and RANKL were produced in physiological amounts that corresponded to $668 \mathrm{pg} / \mathrm{ml}$ OPG and 345 $\mathrm{pg} / \mathrm{ml}$ RANKL, as determined by ELISA. After the addition of TRAIL
(100 ng/ml) to the medium we obtained $328 \mathrm{pg} / \mathrm{ml}$ of OPG compared to $1243 \mathrm{pg} / \mathrm{ml}$ of RANKL.

In summary, we demonstrated the expression pattern of RANKL, and OPG protein in RA synovial fibroblasts, after administration of human recombinant TRAIL $(100 \mathrm{ng} / \mathrm{ml})$. We have described the relationship of the TRAIL-RANKL-OPG axis, suggesting that RA synovial fibroblasts produce a basal level of OPG that interferes with TRAIL, inducing an undisturbed production of RANKL. From these results we suggest that TRAIL is not suitable for a therapeutic role in the treatment of RA.

PAOLA NARDUCCI, Degree in Biological Science, Professor; RENATO BAREGGI, Degree in Pharmaceutical Science, Professor; VANESSA NICOLIN, PhD, Assistant Professor, Department of Biomedicine, University of Trieste, via Manzoni 16, 34138 Trieste, Italy. Address reprint requests to Dr. V. Nicolin; E-mail: nicolin@units.it

\section{REFERENCES}

1. Gravallese EM, Manning C, Tsay A, et al. Synovial tissue in rheumatoid arthritis is a source of osteoclast differentiation factor. Arthritis Rheum 2000;43:250-8

2. Haynes DR, Crotti TN, Capone M, Bain GI, Atkins GJ, Findlay DM. Osteoprotegerin and receptor activator of nuclear factor kappa $B$ ligand (RANKL) regulate osteoclast formation by cells in the human rheumatoid arthritic joint. Rheumatology 2001;40:623-30.

3. Chu CQ, Field M, Allard S, Abney E, Feldmann M, Maini RN. Detection of cytokines at the cartilage/pannus junction in patients with rheumatoid arthritis: implications for the role of cytokines in cartilage destruction and repair. Br J Rheumatol 1992;31:653-61.

4. Chu CQ, Field M, Feldman M, Maini RN. Localization of tumor necrosis factor in synovial tissues and at the cartilage-pannus junction in patients with rheumatoid arthritis. Arthritis Rheum 1991;34:1125-32

5. Vergunst CE, Gerlag DM, Lopatinskaya L, et al. Modulation of CCR2 in rheumatoid arthritis: a double-blind, randomized, placebo-controlled clinical trial. Arthritis Rheum 2008;58:1889-91

6. Tunyogi-Csapò M, Kis-Toth $\mathrm{K}$, Vermes $\mathrm{C}$, et al. The role of synovial fibroblasts in pathologic bone resorption: RANKL and OPG expression by human and mouse fibroblasts in arthritis. Bone 2008;43 Suppl: S40.

7. Takayanagi H, Iizuka H, Juji T, et al. Involvement of receptor activator of nuclear factor B ligand/osteoclast differentiation factor in osteoclastogenesis from synoviocytes in rheumatoid arthritis. Arthritis Rheum 2000;43:259-69.

8. Yasuda H, Shima N, Nakagawa N, et al. Osteoclast differentiation factor is a ligand for osteoprotegerin / osteoclastogenesis-inhibitory factor and is identical to TRANCE/RANKL. Proc Natl Acad Sci USA 1998;95:3597-602.

9. Gravallese EM, Galson D, Goldring SR, Auron PE. The role of TNF-receptor family members and other TRAF-dependent receptors in bone resorption. Arthritis Res 2001;3:6-12.

10. Emery JG, McDonnell P, Burke MB, et al. Osteoprotegerin is a receptor for the cytotoxic ligand TRAIL. J Biol Chem 1998;273:14363-7.

11. Walczak H, Miller RE, Ariail K, et al. Tumoricidal activity of tumor necrosis factor-related apoptosis-inducing ligand in vivo. Nat Med 1999:5:157-63.

12. Walczak H, Degli-Esposti MA, Johnson RS, et al. TRAIL-R2: a novel apoptosis-mediating receptor for TRAIL. EMBO J 1997;16:5386-97.

13. Macfarlane MM, Ahmad SM, Srinivassula T, Fernandes-Alnemri GM, Cohen GM, Alnemri ES. Identification and molecular cloning of two novel receptors for the cytotoxic ligand TRAIL. J Biol Chem 1997;272:25417-20.

14. Colucci S, Brunetti G, Rizzi R, et al. T cells support osteoclastogenesis in an in vitro model derived from human multiple myeloma bone disease: the role of the OPG/TRAIL interaction. Blood 2004;104:3722-30.

J Rheumatol 2009;36:8; doi:10.3899/jrheum.081089 

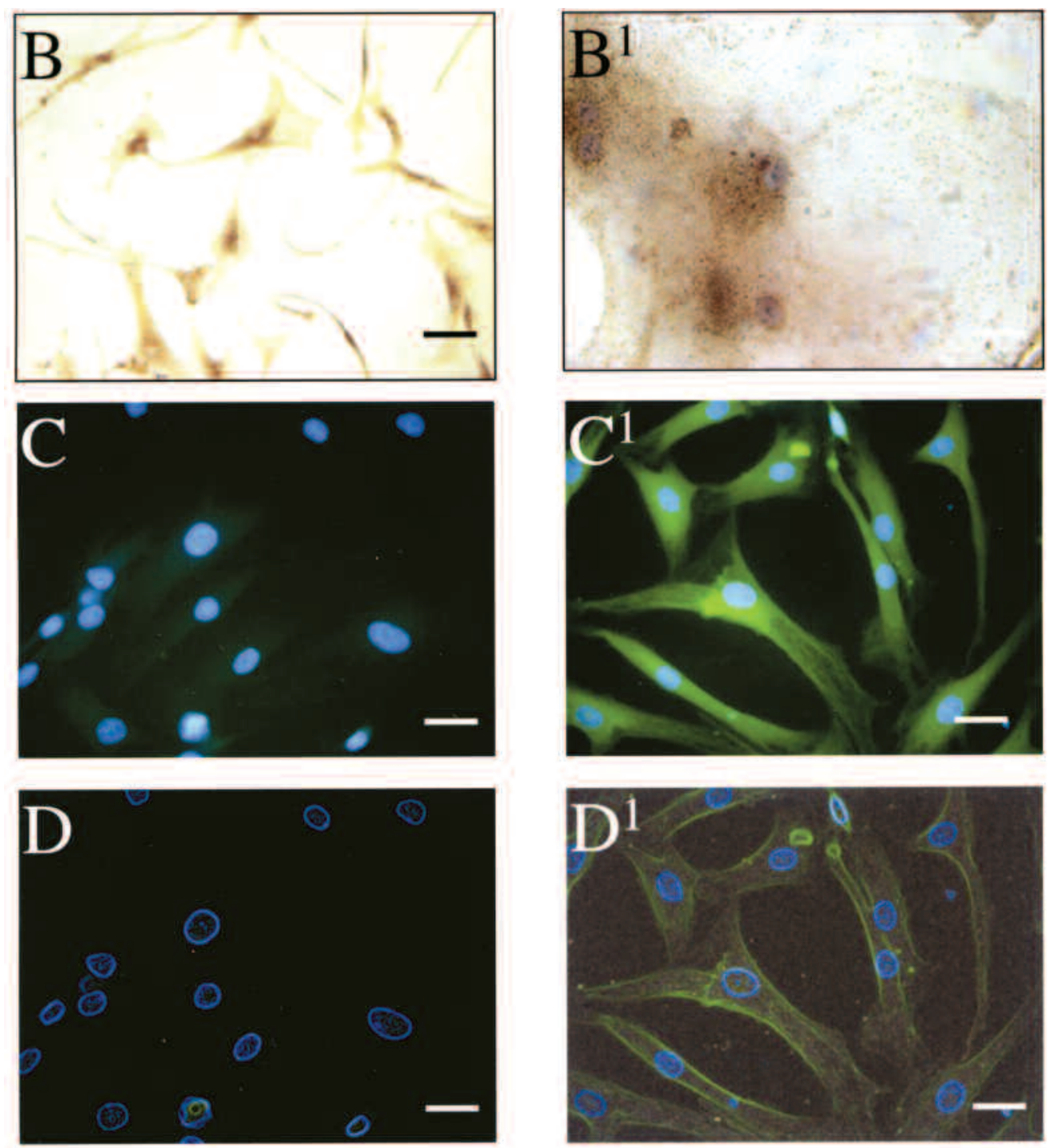

- TRAIL

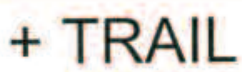

\section{RANKL}

Figure 1. Effect of human recombinant TRAIL on RANKL expression in RA synovial fibroblasts cultured with human recombinant TRAIL (100 $\mathrm{ng} / \mathrm{ml})$ for 4 days. B-B1. Immunoenzymatic assay for TRAP positivity in the presence or absence of human recombinant TRAIL. C-C1. Immunocytochemical expression of RANKL antibody FITC-conjugated and DAPI nuclei staining in the presence $(\mathrm{C} 1)$ or absence $(\mathrm{C})$ of treatment with human recombinant TRAIL (100 $\mathrm{ng} / \mathrm{ml}$ ). D-D1. Image analysis of immunocytochemical expression of RANKL in the presence or absence of human recombinant TRAIL $(100 \mathrm{ng} / \mathrm{ml})$. All the fluorescence images show that synovial cells treated with $100 \mathrm{ng} / \mathrm{ml}$ TRAIL expressed upregulation of RANKL compared to control (-TRAIL). All experiments were done in triplicate. Scale bar $=25 \mu \mathrm{m}$. 


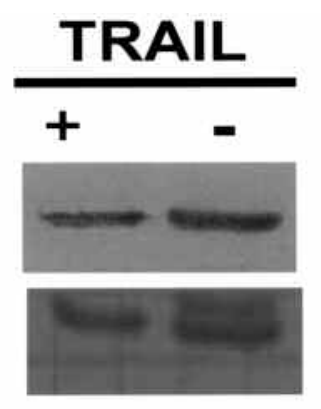

OPG

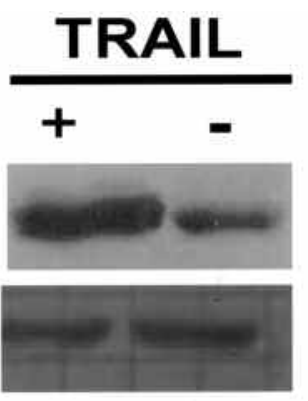

\section{Tubulin}

\section{RANKL}

Figure 2. Effect of human recombinant TRAIL (100 ng/ml) on RANKL and OPG expression in RA synovial fibroblasts. RA synovial fibroblasts were cultured with human recombinant TRAIL (100 $\mathrm{ng} / \mathrm{ml})$ for 4 days. Culture was analyzed, measuring the levels of RANKL and OPG expression in contrast with the control protein tubulin. 